\title{
O manejo da pinta-preta do tomateiro em épocas de temperaturas baixas
}

\author{
Maria Eloísa Salustianoํㅜㄹ Francisco Xavier Ribeiro do Vale², Laércio Zambolim², Paulo César Rezende Fontes ${ }^{3}$.
}

${ }^{1}$ Universidade Federal de Lavras Departamento de Fitopatologia CP- 3037 Lavras CEP 37200-000; ${ }^{2}$ Departamento de Fitopatologia Universidade Federal de Viçosa, CEP 36571-000, Viçosa -MG; ${ }^{3}$ Departamento de Fitotecnia - Universidade Federal de Viçosa, CEP 36571-000, Viçosa-MG; Parte da tese de doutorado do primeiro autor apresentada á Universidade Federal de Viçosa.

*Bolsista do CNPq.

Data de chegada: 16/05/2005. Aceito para publicação em: 03/05/2006.

\begin{abstract}
Salustiano M. E.; Vale F. X.R.V.; Zambolim L.; Fontes P.C.R. Tomato blight management in low temperature periods. Summa Phytopathologica, v.32, n.4, p.353-359, 2006.

The performance of 'Santa Clara' tomato cultivar and of 'Débora Plus' hybrid in relation to blight (Alternaria solani) development during Summer and Autumn under two cropping systems was studied in two experiments carried out in the experimental field of 'Universidade Federal de Viçosa'. Low temperatures, lack of rain or short time of leaf wetting induced low blight incidence and, consequently, neither on of the cropping systems has influenced the

disease severity on both assays. 'Santa Clara' showed higher area under disease progress curve (AUDPC) values in relation to 'Débora Plus'. Application of chlorothalonil during the appearance of the first symptoms associated to the climatic factors delayed disease development in 30 days during Summer-Autumn and Autumn-Winter, reducting blight severity in $22 \%$ and $18 \%$ of AACPD values in both assays, respectively.
\end{abstract}

Additional keywords: Alternaria solani, Lycopersicon esculentum, control, environmental factors.

\section{RESUMO}

Salustiano M. E.; Vale F. X.R.V.; Zambolim L.; Fontes P.C.R. O manejo da pinta-preta do tomateiro em épocas de temperaturas baixas. Summa Phytopathologica, v.32, n.4, p.353-359, 2006.

O desempenho do cultivar de tomate Santa Clara e do híbrido Débora Plus em relação ao desenvolvimento da pinta-preta (Alternaria solani) em plantios de verão e outono sob dois sistemas de condução foi verificado em dois experimentos conduzidos na área experimental da Universidade Federal de Viçosa. Temperaturas baixas, ou escassez de chuva e, ou, curtas durações dos períodos de molhamento foliares propiciaram baixa incidência da pinta-preta e conseqüentemente os sistemas de condução tradicional e tutorado vertical não influíram na severidade nos dois ensaios. O cultivar Santa Clara apresentou maiores valores de área abaixo da curva de progresso da doença (AACPD) em relação ao híbrido Débora Plus. A aplicação do clorotalonil no aparecimento dos primeiros sintomas associado aos fatores climáticos atrasou o desenvolvimento da doença em 30 dias nas estações de verão-outono e outono-inverno com reduções da severidade da pintapreta de $22 \%$ e $18 \%$ dos valores de AACPD nos dois ensaios, respectivamente.

Palavras-chave adicionais: Alternaria solani, Lycopersicum esculentum, controle, fatores ambientais.

O tomateiro (Lycopersicon esculentum Mill.) é cultivado em todo o território brasileiro, abrangendo regiões com diferentes características climáticas, além de diversas formas de sistemas de condução. Também está sujeito à ocorrência de doenças e pragas desde a semeadura até a colheita. Sendo as doenças fúngicas do tomateiro responsáveis por aumento de $30 \%$ no custo de produção atribuído ao uso de fungicidas para combate de doenças foliares (9).

Durante um levantamento em áreas cultivadas com tomate em Minas Gerais constatou-se que entre as doenças de maior incidência estava a pinta-preta (Alternaria solani (Ellis \& Martin) Jones \& Grout), com $88 \%$ seguida da requeima (Phytophthora infestans (Mont.) de
Bary), com $85 \%$. As pulverizações com fungicidas durante o ciclo da cultura para controle dessas doenças atingiam 18 a 20 aplicações para pinta-preta e requeima, respectivamente (13).

A possibilidade de substituição do sistema tradicional por um sistema de menor custo, em que se associam adensamento de plantio e a poda das plantas, foi proposta por Belfort (2). Produções comerciais semelhantes ao sistema tradicional, com a vantagem de facilitar a execução de tratos culturais e do aumento da eficiência no controle de pragas e doenças, foram obtidas com a poda das plantas, após cinco cachos, numa população de 30.000 plantas/ha ou poda após três cachos, numa população de 40.000 plantas/ha. O maior princípio 
implícito na prática da poda é o de que existe relação entre crescimento vegetativo e reprodutivo que determina a época de floração e distribuição de assimilados (8).

Resultados práticos importantes relacionados com o manejo da cultura, como maior facilidade de execução das práticas culturais, redução do volume e maior segurança na aplicação de defensivos, têm sido observados com esse sistema $(3,4,78)$. A associação da poda apical com a maior densidade de plantio mostrou-se economicamente mais vantajosa, em termos de receita líquida por dia de permanência da cultura no campo, do que o sistema tradicional de condução $(3,6$, 7). Este trabalho teve por objetivo comparar o desempenho da variedade Santa Clara e do híbrido Débora Plus em relação ao desenvolvimento da pinta-preta em plantios de verão e outono sob dois sistemas de condução na região de Viçosa.

\section{MATERIAL E MÉTODOS}

As condições climáticas e o desenvolvimento da pinta-preta do tomateiro foram avaliados em dois ensaios de campo na Universidade Federal de Viçosa, em Viçosa, Minas Gerais, no período de agosto de 1997 a agosto de 1998.

A duração dos ensaios 1 e 2 foi de 105 e 121 dias respectivamente, sendo utilizados a variedade Santa Clara e o híbrido Débora Plus. Os ensaios foram conduzidos em delineamento experimental de blocos casualizados, com parcelas subsubdivididas, sendo as parcelas constituídas de dois sistemas de condução (tradicional e tutorado vertical), as subparcelas constituídas da variedade Santa Clara e do híbrido Débora Plus e a subsubparcela constituídas de presença ou ausência de controle com fungicida.

Cada subparcela experimental foi constituída de seis linhas com $3,0 \mathrm{~m}$ de comprimento, espaçadas de $1,0 \mathrm{~m}$. O espaçamento utilizado foi de $1,0 \mathrm{~m}$ entre linhas e $0,3 \mathrm{~m}$ entre plantas, para o sistema tutorado vertical, com o total de 72 plantas em cada subparcela, conduzidas com uma haste por planta. No sistema de condução tradicional, o espaçamento utilizado foi de 1,0 m entre linhas e $0,6 \mathrm{~m}$ entre plantas, com o total de 36 plantas em cada subparcela, conduzidas com duas hastes por planta. Nesses ensaios, foram utilizados quatro blocos e 32 parcelas experimentais.

A parcela experimental útil nos dois ensaios, para avaliação da intensidade da pinta-preta, foi constituída de 10 plantas no sistema tutorado vertical e cinco no sistema tradicional. Essas plantas estavam situadas nas duas linhas centrais de cada parcela. As plantas das extremidades de cada linha foram consideradas bordaduras. Nos ensaios 1 e 2, foram realizadas 8 e 10 aplicações de chlorotalonil (10), na dose de $200 \mathrm{~g}$ i.a./100 L de água, respectivamente. Nos dois ensaios, a primeira aplicação do produto teve início seis semanas após o transplantio, quando houve a manifestação dos primeiros sintomas.

Registro dos dados meteorológicos - O registro dos dados meteorológicos em cada época foi realizado por termohigrógrafo acondicionado em abrigo meteorológico e um sensor de molhamento foliar instalado entre as plantas do tomateiro, à altura de 1,5 m, fixado a um suporte de madeira, na altura do terço médio e entre a folhagem da planta, localizada próxima ao abrigo meteorológico.

Os dados pluviométricos foram coletados na estação climatológica localizada a $500 \mathrm{~m}$ da área experimental. Os dados meteorológicos foram armazenados em computador e analisados, utilizando-se o programa EXCEL.

\section{Quantificação do progresso da doença}

. As avaliações da severidade da pinta-preta foram realizadas semanalmente a partir do aparecimento dos primeiros sintomas, sendo que, no ensaio 1, as avaliações foram realizadas aos 40, 48, 54, 60, 67, 74, 82, 90, 97 e 105 dias após o transplantio (dat), totalizando-se 10 avaliações. No ensaio 2 , as avaliações foram realizadas aos 46, 52, 60 , $67,54,81,88,95,101$ e 108 dat, num total de 12 avaliações. Nos dois ensaios, a severidade foi avaliada nas 10 plantas centrais do sistema tutorado vertical e em cinco plantas centrais do sistema tradicional. Para cálculo da severidade foram monitorados todos os fólios principais de cada folha. Com os dados de severidade de cada folíolo foram calculadas as médias de cada folha. De posse das médias de cada folha foi calculada a média de cada planta. Para auxiliar a avaliação de severidade, foram utilizadas escalas diagramáticas, conforme a escala proposta por BOFF (3).

\section{Epidemiologia comparativa e análise estatística}

Os valores médios de severidade de cada parcela foram convertidos em gráficos de severidade versus tempo para se obter a curva de progresso da pinta-preta nas diferentes épocas e nos diferentes tratamentos.

A severidade média obtida nos ensaios 1 e 2 foi utilizadas para estimar a área abaixo da curva de progresso da doença (AACPD), que foi calculada pela equação proposta por Shaner \& Finney (12):

AACPD $=6\left(\mathrm{Yi}^{\left.\mathrm{i}+\mathrm{Yi+1} /{ }^{2}\right)}\right)\left(\mathrm{t}_{\mathrm{i}+1}-\mathrm{t}_{\mathrm{i}}\right)$, em que i é a severidade da doença na i-ésima observação, Xi é o tempo em dias na i-ésima observação e n é o número total de observações.

Para que os tratamentos dos dois sistemas de condução pudessem ser comparados, foram considerados os dados de severidade para os 90 dat no ensaio 1 e de 108 dias no ensaio 2.

AAACPD foi estimada em cada parcela, em cada repetição, para comparação dos tratamentos pela análise de variância (ANOVA). A análise de variância foi feita, utilizando-se o programa "Statistical Analysis System" (SAS).

Nos ensaios, a descrição das variáveis microclimáticas duas semanas antes do início da doença até o final do ciclo foi plotada em relação ao desenvolvimento da doença, com o objetivo de verificar a influência dessas variáveis no progresso da doença em cada época.

Os dados meteorológicos foram agrupados em médias de sete dias, em temperaturas inferiores ou iguais a $20^{\circ} \mathrm{C}$, de 20 a $30^{\circ} \mathrm{C}$ e maiores que $30^{\circ} \mathrm{C}$, e umidade relativa na presença de molhamento, baseado nas condições favoráveis à pinta-preta.

\section{RESULTADOS E DISCUSSÃO}

O ensaio 1 foi conduzido no período de verão-outono, quando a temperatura predominante foi de 25 a $30^{\circ} \mathrm{C}$, no início do ciclo; no final do ciclo, houve queda da temperatura, com média de cinco horas em temperaturas inferiores ou iguais a $20{ }^{\circ} \mathrm{C}$. O molhamento foliar, associado na maior parte do tempo à umidade relativa entre 76 e $89 \%$, teve duração média de oito horas, e a freqüência de chuva foi maior no início do ensaio. Waggnoer \& Parlange (14) relataram temperaturas mínima, ótima e máxima de 4,28 e $40^{\circ} \mathrm{C}$, respectivamente, enquanto temperaturas menores que 5 e 27 e maior que $35^{\circ} \mathrm{C}$ foram relatadas por Rotem (11). Esse autor ressaltou que, com período de molhamento favorável e na presença de inóculo, as temperaturas mínimas para infecção podem ser reduzidas de $20{ }^{\circ} \mathrm{C}$ para $10{ }^{\circ} \mathrm{C}$, as máximas aumentam de $30^{\circ} \mathrm{C}$ para $35^{\circ} \mathrm{C}$ e as temperaturas ótimas se estendem de um pico de $25{ }^{\circ} \mathrm{C}$ para uma faixa de 20 a $30^{\circ} \mathrm{C}$.

Nesse ensaio, a primeira aplicação de fungicida (45 dat) ocorreu 
após o início da epidemia (40 dat)e a severidade inicial foi de $5 \%$, mantendo-se em níveis inferiores a $10 \%$ até os 54 dat. No referido ensaio, a severidade máxima só foi alcançada no final do ciclo, em que a severidade em plantas que não receberam fungicidas ocorreu sete dias antes daquelas que o receberam. O ciclo da cultura foi sempre menor nas plantas que não receberam aplicação de fungicida (Tabela 4).

Houve ocorrência de temperatura favorável, umidade e molhamento foliar nas duas primeiras semanas do ensaio, favorecendo o início e o desenvolvimento da doença. A temperatura foi favorável durante todo
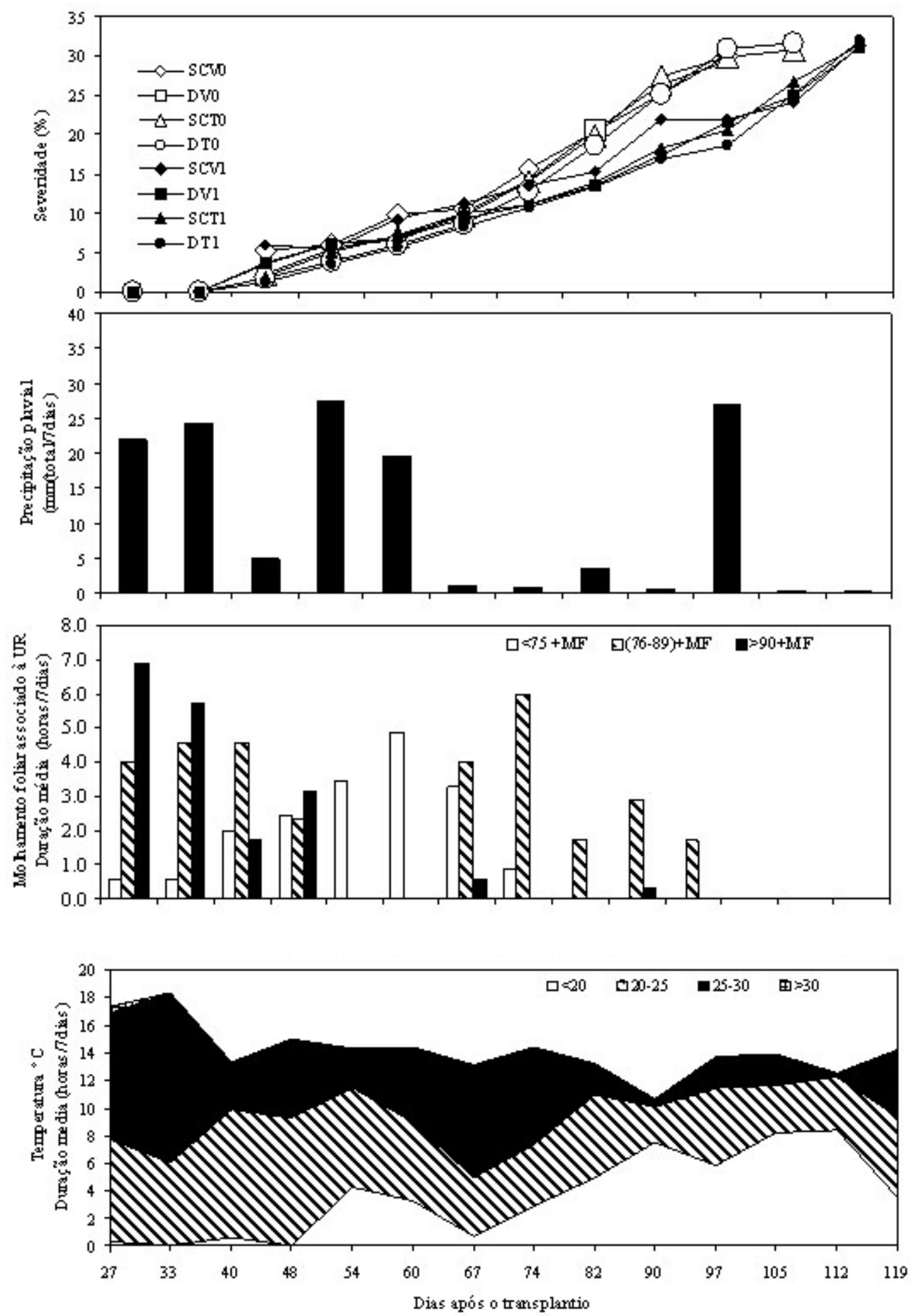

Figura -1 Progresso da pinta-preta do tomateiro (Alternaria solani) no cultivar Santa Clara e no híbrido Débora Plus no sistema de condução tradicional sem controle (SCT0 e DT0), com controle (SCT1 e DT1) e no sistema de condução vertical sem controle (SCV0 e DV0) e com controle (SCV1 e DV1), precipitação pluviométrica semanal e número de horas semanais de molhamento foliar (M.F.) associado à umidade relativa (U.R.) e à temperatura na época 1 (4 fevereiro a 25 de maio de 1998). 
o ensaio, no entanto a ocorrência de chuva foi escassa e a duração do molhamento foliar foi reduzida para três horas semanais (Figura 1). As temperaturas ideais registradas para a ocorrência epidêmica da pinta-preta causada por $A$. solani são de 28 a $32{ }^{\circ} \mathrm{C}$. No entanto, a umidade é necessária para o estabelecimento da epidemia (11).

O desenvolvimento lento da curva de progresso da doença no ensaio 1, com níveis de severidade altos apenas no final do ciclo, deveu-se à redução do período de molhamento foliar, à escassez de chuva e à redução da temperatura a partir dos 60 dat.O efeito de umidade na folha garante a relação umidade versus doença. A umidade relativa alta pode auxiliar na estimativa do molhamento foliar (5). Notou-se ainda que, mesmo com o atraso na primeira aplicação do
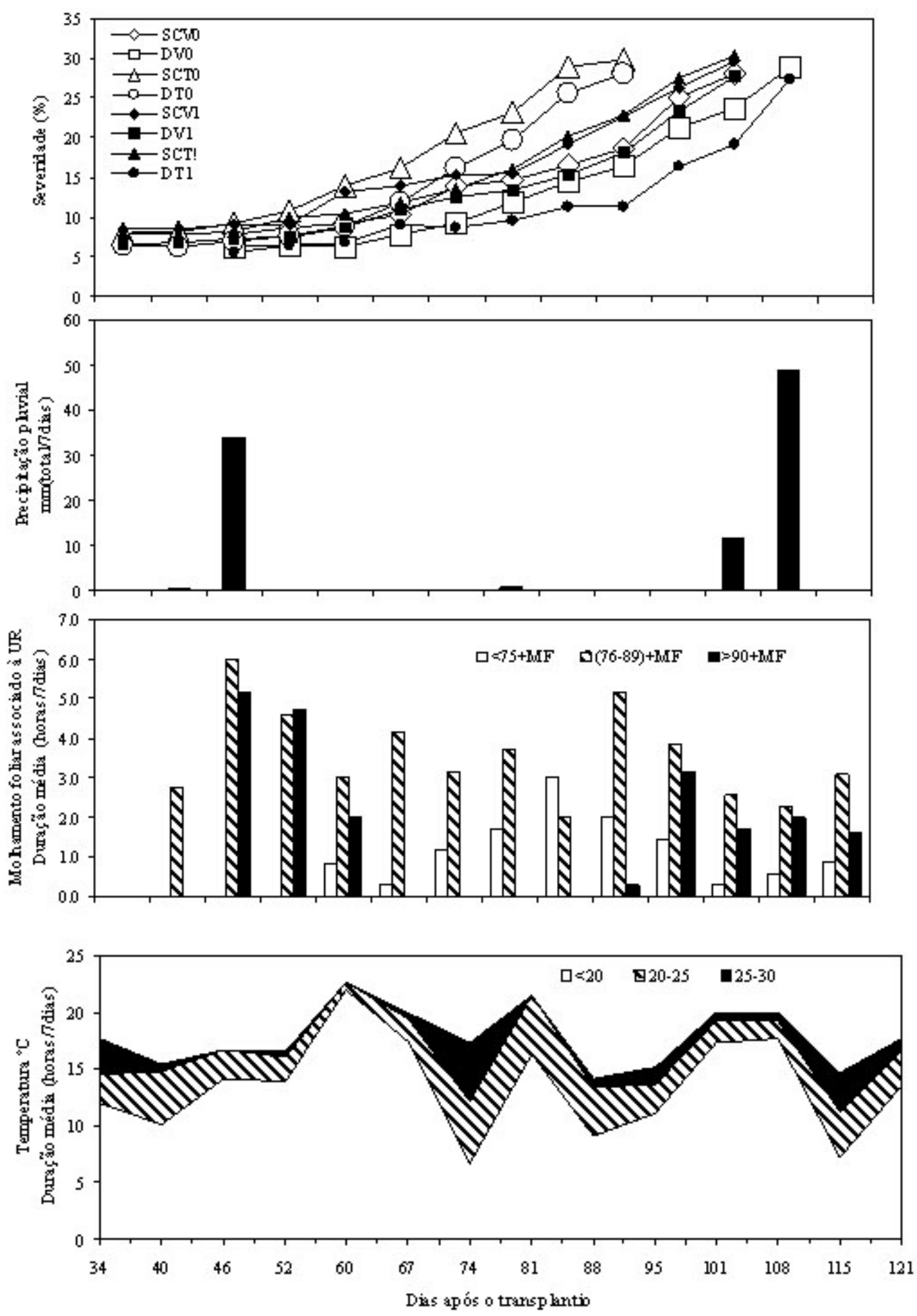

Figura -2 Progresso da pinta-preta do tomateiro (Alternaria solani) no cultivar Santa Clara e no híbrido Débora Plus no sistema de condução tradicional sem controle (SCT0 e DT0), com controle (SCT1 e DT1) e no sistema de condução vertical sem controle (SCV0 e DV0) e com controle (SCV1 e DV1), precipitação pluviométrica semanal e número de horas semanais de molhamento foliar (M.F.) associado à umidade relativa (U.R.) e à temperatura na época 2 (17 abril a 17 de agosto 1998). 
fungicida, houve diferenças na severidade entre as curvas de progresso da doença de plantas que receberam ou não aplicações de fungicida, o que pode ser comprovado pelos valores de AACPD, que foram menores em plantas que receberam fungicida (Tabela 3). O desenvolvimento da curva de progresso da doença no híbrido Débora Plus foi semelhante ao do cultivar Santa Clara (Figura1).

O ensaio 2 foi conduzido no período de outono-inverno. A temperatura nesse período foi inferior ou igual a $20{ }^{\circ} \mathrm{C}$ e houve molhamento foliar durante todo o ensaio e duas ocorrências de chuva durante todo o período. A epidemia iniciou-se aos 46 dat, e a primeira aplicação de fungicida foi aos 45 dat. Apesar de a primeira aplicação ter sido realizada próximo ao início da epidemia, as curvas de progresso da doença só atingiram severidade máxima depois dos 100 dat, na cultivar e no híbrido em estudo. Com relação ao cultivar Santa Clara, plantas que não receberam aplicação de fungicida alcançaram severidade máxima aos 108 dat, enquanto aquelas que receberam alcançaram a severidade máxima aos 121 dat. Plantas do híbrido Débora Plus que não receberam aplicação de fungicida tiveram menor ciclo da cultura e severidade máxima antecipada, em comparação com as plantas que receberam essa aplicação Tabela 4). Neste ensaio, a predominância de temperaturas inferior ou igual a $20^{\circ} \mathrm{C}$ e a falta de chuva foi desfavoráveis à ocorrência da pinta-preta, o que reduziu a severidade, de tal forma que a severidade máxima só ocorreu no final do ciclo dos dois cultivares (Figura 2). A habilidade das espécies de Alternaria em utilizar o orvalho como fonte de umidade excede à de outros fungos, devido à sua resistência em suportar condições adversas entre o momento da dispersão e a queda de orvalho, além da capacidade de esporular e infectar em regimes de orvalho interrompidos por períodos secos (1).

O efeito do fungicida pode ser observado pelos valores de AACPD, que foram menores nas plantas que receberam aplicação de fungicida (Tabela 3). Provavelmente nos plantios futuros com condições ambientais semelhantes haverá maior redução dos níveis de severidade se as aplicações preventivas de fungicida durante o período de outonoinverno forem antecipadas.
As épocas de plantio em que predominam temperaturas entre 20 e $30^{\circ} \mathrm{C}$, com presença de molhamento foliar e chuva na região de Viçosa, favorecem, consideravelmente, a ocorrência da pinta-preta. Plantas do cultivar Santa Clara conduzidas pelo sistema tutorado vertical foram mais suscetíveis à pinta-preta e apresentaram maiores valores de severidade, em comparação com o sistema tradicional de condução de plantas (Figura 1). Nessa época, a doença inicia-se com valores de severidade altos se não receberem aplicação preventiva de fungicida. Tais condições de ambiente favorecem o crescimento rápido da curva de progresso da doença, que atinge níveis de severidade em torno de 20 a 30\%, no meio do ciclo da cultura (Figura 1).

Épocas em que as temperaturas predominantes são menores e iguais a $20^{\circ} \mathrm{C}$, mesmo na presença de molhamento foliar e chuvas, a curva de progresso da doença se desenvolve lentamente e a severidade de 20 a $30 \%$ só é alcançada no final da cultura, quando a produção já atingiu seu máximo.

A severidade da pinta-preta nas épocas 1 (verão-outono) e 2 (outono-inverno) foi atenuada pelas condições ambientais, como temperaturas baixas, ou escassez de chuva e, ou, curta duração do período de molhamento foliar. Nesse período não houve diferenças significativas entre os sistemas de condução de plantas utilizados (Tabela 1), em relação à severidade da doença, provavelmente em razão dos baixos valores de severidade. O sistema de condução não influi na severidade da doença em épocas em que a temperatura é baixa (inferior ou igual a $20{ }^{\circ} \mathrm{C}$ ), a umidade é alta ou as temperaturas são altas, com escassez de chuva e períodos curtos de molhamento foliar(Figura 2).

O cultivar Santa Clara apresentou maiores valores de severidade nos dois ensaios e isso pôde ser comprovado pelos valores de AACPD, que foram maiores no cultivar Santa Clara em relação ao híbrido Débora Plus (Tabela 2). A aplicação de fungicida realizada no aparecimento dos primeiros sintomas resultou em reduções da severidade da pintapreta de $22 \%$ e $18 \%$ dos valores de AACPD nos dois ensaios, respectivamente (Tabela 3 ).

Tabela 1 Ocorrência de pinta-preta (Alternaria solani) em tomateiro, nos sistemas de condução vertical e tradicional.

\begin{tabular}{lcc}
\hline Tratamentos & AACPD $^{1}$ & AACPD $^{2}$ \\
Sistema tradicional & $623 \mathrm{a}$ & $811 \mathrm{a}$ \\
Sistema vertical & $689 \mathrm{a}$ & $783 \mathrm{a}$ \\
\hline
\end{tabular}

Médias seguidas da mesma letra nas colunas não diferem entre si pelo teste $\mathrm{F}(\mathrm{P}<0.05)$.

1 ensaio -1 (verão-outono)

2 ensaio - 2 (outono- inverno)

3 AACPD - Área abaixo da curva de progresso da doença.

Tabela 2 Ocorrência de pinta-preta (Alternaria solani) em tomateiro na cultivar Santa Clara e o híbrido Débora Plus.

\begin{tabular}{lcc} 
Tratamentos & AACPD $^{1}$ & AACPD $^{2}$ \\
Cultivar Santa Clara & $687 \mathrm{a}$ & $886 \mathrm{a}$ \\
Híbrido Débora Plus & $625 \mathrm{~b}$ & $708 \mathrm{~b}$ \\
\hline
\end{tabular}

Médias seguidas da mesma letra nas colunas não diferem entre si pelo teste $\mathrm{F}(\mathrm{P}<0.05)$.

1 ensaio - 1 (verão-outono)

2 ensaio - 2 (outono- inverno)

3 AACPD - Área abaixo da curva de progresso da doença. 
Tabela 3 Ocorrência de pinta-preta (Alternaria solani) em tomateiro na presença e ausência de clorotalonil.

\begin{tabular}{|c|c|c|}
\hline Tratamentos & $\mathrm{AACPD}^{1}$ & $\mathrm{AACPD}^{2}$ \\
\hline Com fungicida & 573 a & $718 \mathrm{a}$ \\
\hline Sem fungicida & $2956 \mathrm{~b}$ & $876 \mathrm{~b}$ \\
\hline
\end{tabular}

Médias seguidas da mesma letra nas colunas não diferem entre si pelo teste $\mathrm{F}(\mathrm{P}<0.05)$.

1 ensaio -1 (verão-outono)

2 ensaio - 2 (outono- inverno)

3 AACPD - Área abaixo da curva de progresso da doença.

Tabela 4. Resumo das avaliações de controle da pinta-preta do tomateiro (Alternaria solani) realizadas nos ensaios 1 e 2 na cultivar Santa clara e no híbrido Débora Plus. Viçosa - 1998.

\begin{tabular}{|c|c|c|c|c|c|c|c|c|}
\hline & $\begin{array}{l}\text { Época de } \\
\text { Transplantio }\end{array}$ & $\begin{array}{l}\text { Início da } \\
\text { Epidemia } \\
\text { (dat) }\end{array}$ & $\begin{array}{c}\text { Número de Aplicaçōes } \\
\text { de Fungicidas }\end{array}$ & $\begin{array}{c}\text { Primeira Aplicaçáa } \\
\text { de Fungicida } \\
\text { (dat) }\end{array}$ & $\begin{array}{l}\text { Severidade } \\
\text { Máxima } \\
\% \text { (dat) }\end{array}$ & $\begin{array}{l}\text { Taxa de } \\
\text { Infecçiōo } \\
\text { (dat) }\end{array}$ & $\begin{array}{l}\text { AACPD } \\
\text { (90dias) }\end{array}$ & $\begin{array}{c}\text { Ciclo da Cultura } \\
\text { (dat) }\end{array}$ \\
\hline ENSAIO 1 & $04 / 02 / 98$ & 40 & 8 clorotalonil & 45 & & & & \\
\hline SCV0 & • & - & • & $\cdot$ & $30(90)$ & $0,73(60)$ & 774 & 97 \\
\hline SCV1 & - & - & - & - & $24(97)$ & $0,83(74)$ & 663 & 105 \\
\hline SCT0 & - & . & - & - & $30(97)$ & $0,96(74)$ & 740 & 97 \\
\hline SCT1 & - & - & - & - & $31(105)$ & $0,88(90)$ & 563 & 105 \\
\hline DV0 & - & - & - & - & $29(90)$ & $0,88(67)$ & 743 & 90 \\
\hline DV1 & - & - & - & - & $31(105)$ & $0,77(97)$ & 565 & 105 \\
\hline DT0 & - & . & - & - & $31(97)$ & $0,84(67)$ & 817 & 97 \\
\hline DT1 & - & - & - & - & $32(105)$ & $0,93(97)$ & 629 & 105 \\
\hline ENSAIO 2 & $17 / 04 / 97$ & 46 & 10 clorotalonil & 45 & & & & \\
\hline SCV0 & • & - & • & $\cdot$ & $28(108)$ & $1,08(95)$ & 925 & 108 \\
\hline SCV1 & - & - & - & - & $29(121)$ & $0,61(95)$ & 820 & 121 \\
\hline SCT0 & - & - & - & - & 29 (108) & $0,97(95)$ & 1023 & 108 \\
\hline SCT1 & - & - & - & - & $30(121)$ & $0,69(108)$ & 775 & 121 \\
\hline DV0 & - & - & - & - & $28(115)$ & $0,82(95)$ & 741 & 115 \\
\hline DV1 & - & . & - & - & $27(121)$ & $0,75(115)$ & 649 & 121 \\
\hline DT0 & - & - & - & - & $28(108)$ & 0,99 (95) & 818 & 108 \\
\hline DT1 & - & - & - & - & $27(115)$ & $1,17(108)$ & 629 & 115 \\
\hline
\end{tabular}

SCV0 - Cultivar Santa Clara, sistema de condução tutorado vertical com fungicida.

SCV1 - Cultivar Santa Clara, sistema de condução tutorado vertical sem fungicida.

SCT0 - Cultivar Santa Clara, sistema de condução tradicional com fungicida.

SCT1 - Cultivar Santa Clara, sistema de condução tradicional sem fungicida.

DV0 - Híbrido Débora Plus, no sistema de condução tutorado vertical com fungicida.

DV1 - Híbrido Débora Plus, no sistema de condução tutorado vertical sem fungicida.

DT0 - Híbrido Débora Plus, no sistema de condução tradicional com fungicida.

DT1 - Híbrido Débora Plus, no sistema de condução tradicional sem fungicida.

dat - Dias após o transplanto.

\section{REFERÊNCIA BBLIOGRAFICA}

1. Bashi, e.; Rotem, J. Indution of sporulation of Alternaria porri f. sp. solani in vivo. Physiology Plant Pathology, New York, v.8, p. 83-90, 1976.

2. Belfort, C. C. Efeito da poda da haste principal e população de plantas sobre a produção de frutos e sementes do tomateiro (Lycopersicon esculentum Mill.) 1979. 45f.. Dissertação (Mestrado em Fitotecnia) - Universidade Federal de Viçosa, Viçosa.

3. Boff, P. Epidemiologia e controle químico da mancha-de-estenfílio (Sthemphylium solani Weber) e da pinta-preta (Alternaria solani Jones \& Grout), em dois sistemas de condução do tomateiro (Lycopersicon esculentum Mill). 1988. 140f. Disserta- ção (Mestrado em Fitopatologia) - Universidade Federal de Viçosa, Viçosa.

4. Campos, J. P.; Belfort, C. C.; Galvão, J. D., Efeito da poda de haste e da população de plantas sobre a produção do tomateiro. Revista Ceres, Viçosa, v. 34, n. 192, p. 198-208, 1987.

5. Datar, V. V.; Mayee, C. D. Epidemiology of early blight of tomato caused by Alternaria solani. Indian Phytopathology, Lucknow, v. 35, n. 4, p. 434, 1981.

6. Fontes, P.C.R.; Nazar, R.A.; Campos, J.P. Adensamento, tutoramento e poda, uma associação viável para a cultura do tomateiro em região quente e chuvosa da Zona da Mata. Belo Horizonte: EPAMIG, 1985. 2p. (Pesquisando, 156).

7. Fontes, P.C.R.; Nazar, R.A.; Campos, J.P. Produção e rentabilidade 
da cultura do tomateiro afetadas pela fertilidade e pelo sistema de condução. Revista Ceres, Viçosa, v. 34, n. 194, p. 355-365, 1987.

8. Gusmão, S. A. L. Efeito da poda e da densidade de plantio sobre a produção do tomateiro (Lycopersicon esculentum Mill) 1988. 103f. Dissertação (Mestrado em Fitotecnia) - Universidade Federal de Viçosa, Viçosa..

9. Lopes, C.A.; Santos, J.R.M. Doenças do tomateiro. Brasília: CNPH EMBRAPA, 1994. 67p.

10. Lukens, R. J.;Ou, S.H. Chlorothalonil residues on field tomatoes and protection against Alternaria solani. Phytopathology, St. Paul, v. 66, n. 8 , p. $1018-22,1985$.
11. Rotem, J. The genus alternaria. Biology, epidemiology, and pathogenicity. St. Paul: APS PRESS, 1994. 326p.

12. Shaner, G.; Finney, R.E. The effect of nitrogen fertilization on the expression of slow-mildewing resistance in knox wheat. Phytopathology, St. Paul, v.70, n. 1, p.1183-1186, 1977.

13. Vale, F. X. R.; Zambolim, L., Chaves, G. M. Avaliação fitossanitária da cultura do tomateiro em regiões produtoras de Minas Gerais e Espírito Santo. Fitopatologia Brasileira, Brasília, v. 17, Suplemento... n. 2, p. 211, 1992 .

14. Waggoner, P. E.; Parlange, J. Y. Slowing of spore germination with changes between moderately warm and cool temperatures. Phytopathology, St. Paul, v. 65, n. 1, p. 551-553, 1975. 